\title{
Capacity Recovery Effect in Lithium Sulfur Batteries for Electric Vehicles
}

\author{
Christian Maurer ${ }^{1}$ * , Walter Commerell ${ }^{1}$, Andreas Hintennach ${ }^{2}$ and Andreas Jossen ${ }^{3}$ (i) \\ 1 Hochschule Ulm (HS Ulm), Prittwitzstr. 10, 89075 Ulm, Germany; commerell@hs-ulm.de \\ 2 Daimler AG, HPC G012, Hanns-Klemm-Str. 45, 71034 Böblingen, Germany; \\ andreas.hintennach@daimler.com \\ 3 Institute for Electrical Energy Storage Technology, Technische Universität München (TUM), Arcisstr. 21, \\ 80333 Munich, Germany; andreas.jossen@tum.de \\ * Correspondence: c.maurer@hs-ulm.de
}

Received: 16 May 2018; Accepted: 10 August 2018; Published: 17 August 2018

\begin{abstract}
Lithium sulfur batteries have a promisingly high theoretical specific energy density of about $2600 \mathrm{Wh} / \mathrm{kg}$ and an expected practical specific energy density of about 500-600 Wh/ kg. Therefore, it is a highly promising future energy storage technology for electric vehicles. Beside these advantages, this technology shows a low cell capacity at high discharge currents. Due to the capacity recovery effect, up to $20 \%$ of the total cell capacity becomes available again with some rest time. This study shows a newly-developed capacity recovery model for lithium sulfur batteries. Due to the long rest periods of electric vehicles, this effect has an important influence on the usable cell capacity and depth of discharge in lithium sulfur batteries.
\end{abstract}

Keywords: battery; discharge rate; capacity recovery; lithium sulfur; modeling

\section{Introduction}

Lithium sulfur batteries (LiS) are a highly promising future energy storage technology for electric vehicles, due to the very high theoretical specific energy density of about $2600 \mathrm{Wh} / \mathrm{kg}$. One reason therefore is the high specific capacity of $1675 \mathrm{Ah} / \mathrm{kg}$ of the sulfur cathode. The theoretical specific energy density is five-times higher than state of the art lithium-ion technologies, and the expected practical specific energy density is about $500-600 \mathrm{Wh} / \mathrm{kg}$ [1].

Furthermore, the potential of low manufacturing costs due to less expensive cathode materials increases their value even more. In state of the art lithium nickel manganese cobalt oxide cells, the cathode results in $24 \%$ of the total cell costs [2].

Despite these strong advantages, LiS technology faces some challenges before it can be used in real applications. To start with, LiS technology has a high degradation rate. The high specific densities can only be reached in the first few full cycles of this technology. After 50-200 full cycles, the usable cell capacity is less than $80 \%$ of its initial cell capacity [3]. A key mechanism of this capacity loss is the huge dilatation of the cell. One reason for this dilatation is a volume change factor of 1.79 from pure sulfur educt $S_{8}$ to the lithium sulfur product $L i_{2} S$ [4].

Another challenge is the multiple redox reactions in LiS batteries compared to lithium ion batteries. The reactivity and reaction kinetics decrease with increasing depth of discharge (DOD) [5]. The redox reactions consist of decreasing polysulfide chains, which precipitate in the final lithium polysulfide $\mathrm{Li}_{2} \mathrm{~S}$ product. Equation (1) shows the overall redox reaction and Equation (2) the simplified assumed multiple redox reaction equations [5].

$$
16 \mathrm{Li}+\mathrm{S}_{8} \rightarrow 8 \mathrm{Li} \mathrm{i}_{2} \mathrm{~S}
$$




$$
\begin{aligned}
\mathrm{S}_{8}+2 \mathrm{Li}^{+}+2 e^{-} & \rightarrow \mathrm{Li}_{2} \mathrm{~S}_{8} \\
\mathrm{Li}_{2} \mathrm{~S}_{8}+2 \mathrm{Li}^{+}+2 e^{-} & \rightarrow 2 \mathrm{Li}_{2} \mathrm{~S}_{4} \\
\mathrm{Li}_{2} \mathrm{~S}_{4}+2 \mathrm{Li}^{+}+2 e^{-} & \rightarrow 2 \mathrm{Li}_{2} \mathrm{~S}_{2} \\
\mathrm{Li}_{2} \mathrm{~S}_{4}+6 \mathrm{Li}^{+}+6 e^{-} & \rightarrow 4 \mathrm{Li} \mathrm{i}_{2} \mathrm{~S}
\end{aligned}
$$

The main occurrences of these reaction products are presented in Figure 1 over DOD.

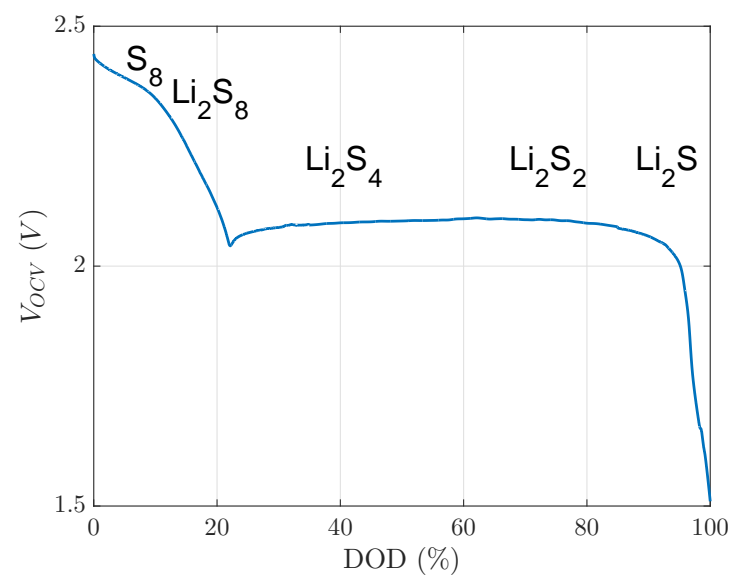

Figure 1. Open circuit voltage of a lithium sulfur cell with reaction products of the multiple reaction stages described in [5]. DOD, depth of discharge.

This open circuit voltage in Figure 1 consists of an upper or first voltage plateau, which ranges from $0 \%$ DOD to $22 \% \mathrm{DOD}$, and a lower or second voltage plateau, which ranges from $22 \%$ DOD to $100 \%$ DOD, as presented in Figure 1. Some LiS-dependent mechanisms can be assigned to the specific plateaus. For instance, only in the first plateau, a very high self-discharge rate is observed because of the shuttle effect $[4,6]$. In the second voltage plateau, $L i_{2} S$ is precipitated [5]. Only $L i_{2} S$ is precipitated as a solid product in LiS cells, as published in [7].

A further challenge for the LiS technology is the sulfur utilization. This utilization is bound to decrease with increasing discharge current. Therefore, the utilized sulfur influences the usable cell capacity, as shown in Figure 2. Taking into account the constant discharge currents and the usable cell capacities, an empiric Peukert coefficient of 1.2 is calculated, as shown in Figure 2.

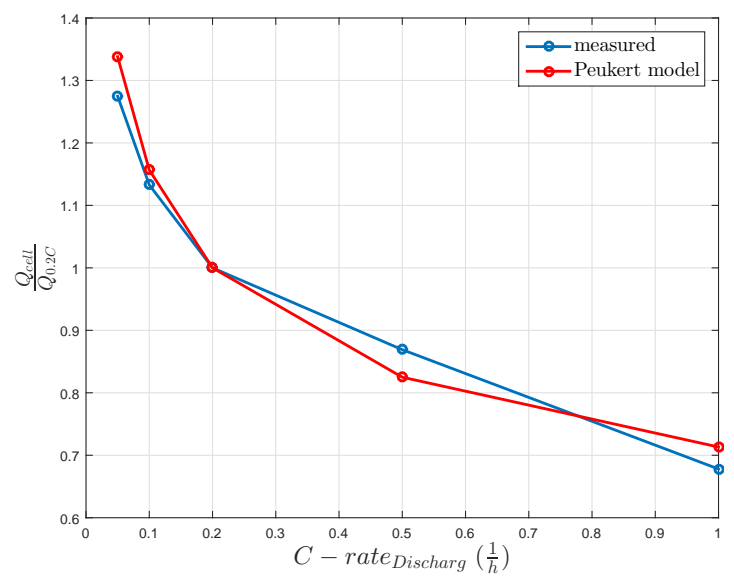

Figure 2. Relative cell capacity influenced by constant discharge current without rest time. The Peukert coefficient of the model is 1.2 . 
The non-utilized sulfur in the LiS technology shows an interesting effect, that parts of this non-utilized sulfur become available during rest times. This sulfur additionally takes part in further discharging. The capacity due to this sulfur is considered as recovered capacity. This is a common effect [8] and has been briefly reported for LiS batteries in $[9,10]$.

However, very little is known about the influence of DOD with a variety of discharge currents on the recovered capacity. This study investigates the DOD-dependent capacity recovery effect.

\section{Capacity Recovery Effect}

This section reflects the dynamic capacity recovery effect. A basic necessity for vehicular evaluations of LiS technology are dynamical and utilizable models. In [11], a dynamical RC-model was published. A first mathematical model of LiS cells was published in [12]. In addition, Marinescu et al. invented a simplified chemical model to describe the discharge and charge reaction mechanisms [13]. So far, the recovery effect of a single DOD as an additional result of a self-discharge experiment was published in [10]. Furthermore, a remarkable recovery effect at a 100\% DOD level was published in [9]. The purpose of this work is the quantification of the recovering capacity of the cell and subsequently its veritable usage capacity. Additionally, a dynamical capacity recovery model for LiS cells from a vehicular application point of view is developed. In vehicular applications, rest times are not connected to specific DODs. In other words, the occurrence of recovery break times $\left(t_{R B T}\right)$ for the recovery effect are DOD independent. In addition, the recovered capacity is quite important to estimate the true usable cell capacity in LiS cells used in electric vehicles.

As described before, the recovered capacity depends on sulfur utilization. We hypothesize that the final product $L i_{2} S$ of the reaction mechanism blocks sulfur and reaction products $L i_{2} S_{x}, 2 \leq x \leq 8$ in the carbon pores. These blocked products are one reason for the poor sulfur utilization and the huge difference between theoretical and practical cell capacity. The sulfur utilization and therefore the blocked products also depend on the carbon pore size [1], which are not known for the used cells. Further, it is believed that the diffusion of dissolved polysulfides away from electrochemical active surfaces leads to low sulfur utilization [14]. Therefore, we assume that this $L i_{2} S$ product diffuses with the time and unblocks active materials in some of the carbon matrix pores, and we assume that dissolved polysulfides diffuse back to the active surface. This unblocking process is influenced by six parameters. First, the diffusion is bound to the initial diffusion rate of the cell. Second, the temperature influences the diffusion rate of the blocking $L i_{2} S$ and the diffusion of polysulfides. Third, the current history influences the precipitated structure of $L i_{2} S$. Fourth, $t_{R B T}$ defines the amount of diffused $L i_{2} S$ and diffused polysulfides. Fifth, the DOD determines the concentration of $L i_{2} S$. Sixth, the cell degradation determines the usable and available active material. To clarify, these parameters cannot be regarded solely. Moreover, there exist dependencies between these parameters. It is clear that this effect is relevant in vehicular applications.

The published time constants for the recovered capacity differ highly. On the one hand, a capacity recovery time constant between 18 and 24 min was published in [9]. In their study, an Oxis 3.4 Ah pouch cell was measured at a constant temperature of $30^{\circ} \mathrm{C}$, and the cell was discharged at $1 \mathrm{C}$. The recovered capacity was measured after recovery break times $t_{R B T}$ up to $4 \mathrm{~h}$ at $100 \%$ DOD. On the other hand, in [10], a capacity recovery time constant of $50 \mathrm{~h}$ was published. There, a single 2.8-Ah Sion Power pouch cell was used in a self-discharge experiment at 60\% DOD and a constant temperature of $20{ }^{\circ} \mathrm{C}$. The cell was discharged at C/9 and, afterwards, charged to $60 \%$ DOD. The recovered capacity after $24 \mathrm{~h}$ of this cell was used to estimate the capacity recovery time constant. Despite the different temperatures and different currents, these findings differ highly. Therefore, a separate first investigation is performed.

\section{Experimental Capacity Recovery Study}

In this section, the experimental design of the capacity recovery study is described. We intend to examine the capacity recovery effect with respect to discharge current, DOD and recovery break time. 


\subsection{Recovery Time Constant}

As noted above, the published recovery time constants differ highly. Therefore, in this section, we intend to analyze the recovery time constant in a first investigation. Therefore, we use a capacity recovery cycle, which consists of four cycles. The first cycle discharges and charges the cell at a nominal $0.2 \mathrm{C}$ discharge and a nominal $0.1 \mathrm{C}$ charge current. This cycle sets the cell in a reproducible condition. The second cycle discharges the cell at $0.8 \mathrm{C}$ discharge current for the recovery reference capacity and charges the cell at a nominal $0.1 \mathrm{C}$ charge current. The third cycle is the same as the first. In the fourth cycle, the cell is at first discharged at $0.8 \mathrm{C}$ discharge current, rests at a DOD of $100 \%$ for a $t_{R B T}$ and discharges the cell a second time at $0.8 \mathrm{C}$ discharge current. The cumulated capacity of the first and the second discharge is the capacity of the fourth cycle, which consists of the constant current discharged capacity and the recovered capacity. Afterwards the cell is charged at a nominal $0.1 \mathrm{C}$ charge current. This recovery cycle was repeated with a linear increasing $t_{R B T}$ from 0-120 min. This first investigation was done in a climate chamber at a constant temperature of $25^{\circ} \mathrm{C}$. The recovered capacity was calculated using Equation (3) by the subtraction of the cell capacity of the fourth cycle after its second discharge and the cell capacity of the second cycle. In order to estimate a recovery time constant, the recovered capacity was modeled using Equation (5). We illustrated the recovered capacities in Figure 3. The least-squares method calculated the gain factor $k$ of $10.5 \%$ and the recovery time constant $\tau$ of $46 \mathrm{~min}$ used in Equation (5) for this first investigation. This result is within the range of [9].

$$
Q_{\text {Rec }}=Q_{4 t h} \text { cycle }-Q_{2 n d} \text { cycle }
$$

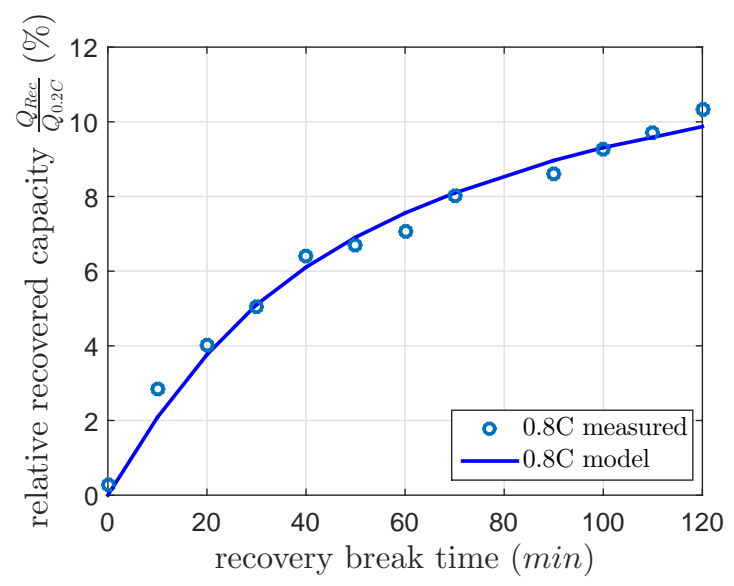

Figure 3. Measured and modeled recovered capacity after a $0.8 \mathrm{C}$ constant current discharge at $100 \%$ DOD and a recovery break time between zero and $120 \mathrm{~min}$ at a constant temperature of $25^{\circ} \mathrm{C}$.

\subsection{Recovery Cycle}

The model proposed in this work calculates the gained cell capacity due to the recovery effect and the $t_{R B T}$. Therefore, a DOD, current and $t_{R B T}$-dependent function is evaluated (see Equation (5)).

In order to quantify the recovered capacity, we have chosen to set up a recovery cycle, which is quite similar to the described recovery cycle in Section 3.1. In contrast with the noted recovery cycle above the second and fourth cycle differ, the fixed discharge current at $0.8 \mathrm{C}$ in Section 3.1 is replaced in this investigation by varied discharge currents. Therefore, the second cycle discharges the cell at a varied discharge current in order to get the reference capacity at the used discharge current and charges the cell at a nominal $0.1 \mathrm{C}$ charge current. In the fourth cycle, the cell is at first partly discharged at the same varied discharge current as in the second cycle. At a specific DOD level, a varied $t_{R B T}$ is included. During this, $t_{R B T}$ capacity is recovered and extends the usable capacity of the cell. After this 
$t_{R B T}$, the cell is further discharged at the varied discharge current until the lower voltage limit of $1.7 \mathrm{~V}$ is reached. Afterwards, the cell is charged again at a nominal $0.1 \mathrm{C}$ charge current. This measurement sequence is shown in Figure 4 for a single recovery cycle.

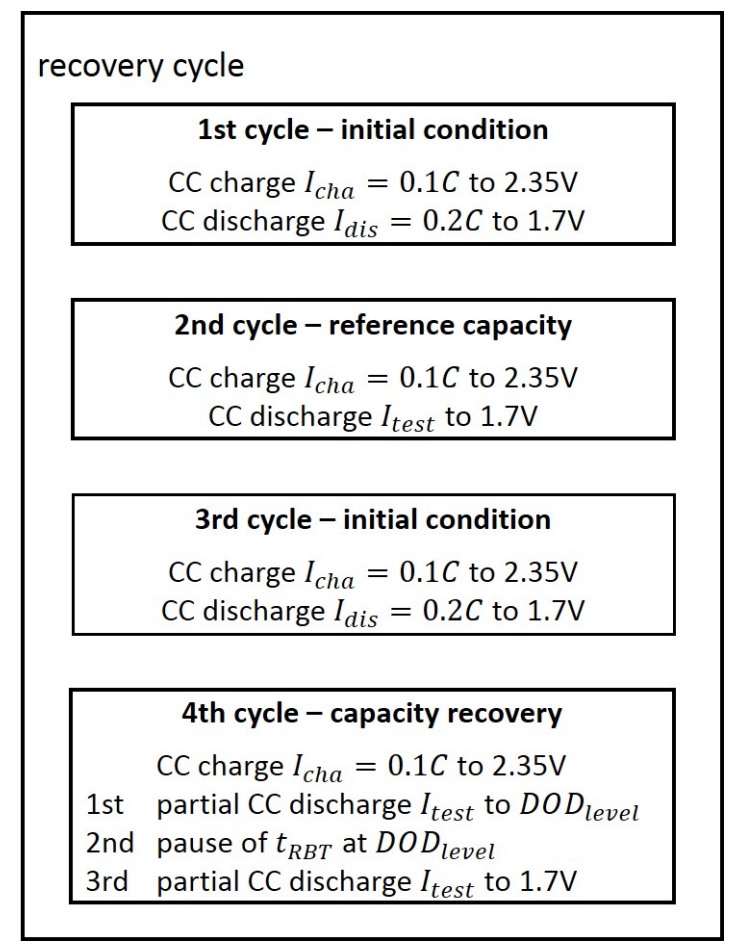

Figure 4. Sequence of the recovery cycle, which consists of four single cycles with constant current (CC) discharges and charges. The test parameters are constant within one recovery cycle. These test parameters are $I_{\text {test }}(0.2,0.4$ or $0.8 \mathrm{C}), \mathrm{DOD}_{\text {level }}(20 \%, 40 \%, 60 \%$ or $80 \%)$ and $t_{R B T}(15 \mathrm{~min}, 30 \mathrm{~min}$, $60 \mathrm{~min}$ or $120 \mathrm{~min})$.

In order to reduce the cell degradation mentioned in Section 1 and reach more comparable results, each cycle is limited by a maximal voltage of $2.35 \mathrm{~V}$ and a minimal voltage of $1.7 \mathrm{~V}$. Furthermore, the additives of the electrolyte are mainly decomposed at voltages near the limits, as demonstrated in [15].

Therefore, the referenced cell capacity is also measured between these voltage limits at a nominal $0.2 \mathrm{C}$ discharge current.

The experiment is done in a climate chamber at a constant temperature of $25^{\circ} \mathrm{C}$. The cells were cycled by a BaSyTec CTS with 32 channels.

\subsection{Parameter Variation}

Three parameters are varied in this capacity recovery study. The first parameter is $t_{R B T}$. Based on the feedback of the recovery time constant investigation (see Figure 3), four $t_{R B T}$ were chosen. In order to get an applicable model, particular attention was paid to lower $t_{R B T}$ with $15 \mathrm{~min}, 30 \mathrm{~min} 60 \mathrm{~min}$ and $120 \mathrm{~min}$.

The second parameter, DOD, was chosen to change in four equally-spaced steps from 20-80 percent with respect to the defined upper and lower voltage limits of this investigation. These DOD levels are all located in the lower plateau with respect to voltage limits of this investigation. Different lithium polysulfides $L i_{2} S_{n} 1 \leq n \leq 8$ exist in the second plateau [5]. The highest recovered capacity is expected at the highest DOD level because of the increasing concentration of precipitated $\mathrm{Li}_{2} \mathrm{~S}$ during the discharge process in the second plateau. Therefore, in every recovery cycle, one DOD level is tested with one $t_{R B T}$. 
The third parameter is the discharge current. Three varied discharge currents $0.2 \mathrm{C}, 0.4 \mathrm{C}$ and $0.8 \mathrm{C}$ were used to measure the recovered capacity. We assumed that the amount of recovered capacity increased at higher discharge currents because of the less homogeneous precipitated $L i_{2} S$ structure.

\subsection{Basic Recovery Model}

The cell capacity is highly current dependent, as shown in Figure 2 and as described in Sections 1 and 2. Part of the blocked capacity can be recovered. The recovered capacity is calculated using Equation (4) by subtraction of the cumulated discharged capacity of the fourth cycle and the discharged capacity of the second cycle of the same cell (Section 3.2). The recovery model is built using Equations (4) and (5).

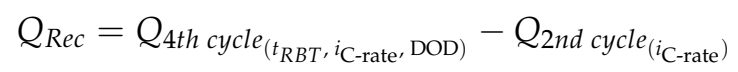

The first recovery time constant investigation presented in Section 3.1 motivated modeling the recovery capacity by Equation (5).

$$
Q_{\operatorname{Rec}}=k e^{-\frac{t_{R B T}}{\tau}}
$$

\section{Results}

\subsection{Constant Current Condition}

This section focuses on the model and the results of the recovery capacity investigation. The gain factor $k$ and the time constant $\tau$ as defined in Equation (5) were estimated by the least-squares method to build the model in the best possible quality. The estimated models are shown in Figure 5 dependent on the gain factor and time constant. All recovered capacities in Figure 5 were normalized capacities by the nominal capacity at $0.2 \mathrm{C}$ constant discharge current.
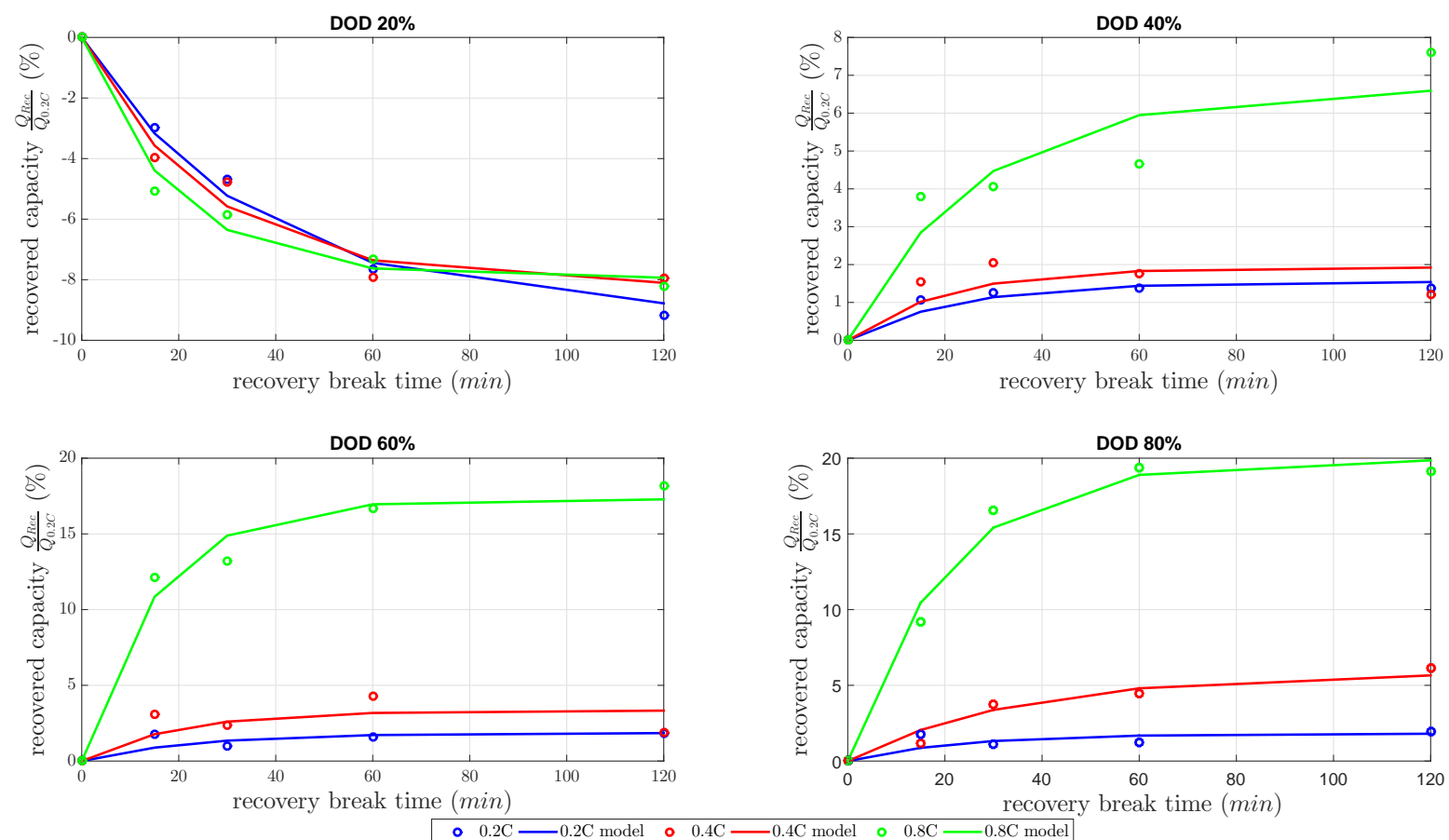

Figure 5. Model of the relative recovered cell capacities at 20\%, 40\%, 60\%, 80\% DOD level and discharge currents of $0.2 \mathrm{C}, 0.4 \mathrm{C}, 0.8 \mathrm{C}$ measured at a constant temperature of $25^{\circ} \mathrm{C}$.

At DOD 20\%, the measurements showed a negative recovered capacity for every discharge current. At that DOD, the cell capacity showed a high decrease of about $8 \%-9 \%$ at $120 \min t_{R B T}$. Therefore, the inclusion of $t_{R B T}$ at a low DOD level decreased the discharged capacity compared to the same varied 
constant current discharge without $t_{R B T}$. The investigated $20 \%$ DOD level was already in the second plateau, with respect to voltage limits of this investigation, as Figure 1 shows. In the second plateau at a $20 \%$ DOD level, precipitated $\mathrm{Li}_{2} \mathrm{~S}$ existed at a low concentration [5]. Nevertheless, this small concentration of $L i_{2} S$ did not block much active material, which could be unblocked by the recovery effect during $t_{R B T}$. In other words, the recovery effect did not explain the decreased discharged capacity. The cell temperature was considered next. It is well known that the cell temperature has a high influence on the discharge capacity in LiS cells. One reason for this influence is the high amount of electrolyte in LiS cells. $t_{R B T}$ forced the inner cell temperature to return to temperature equilibrium conditions and reduced cell kinetics based on the Arrhenius law. Consequently, these findings showed contrary mechanisms between the recovered capacity during the $t_{R B T}$ and the decreasing inner cell temperature during the $t_{R B T}$. Therefore, the lower inner cell temperature reduced the discharged capacity more than the capacity recovered due to unblocked active materials. In other words, the concentration of precipitated $\mathrm{Li}_{2} \mathrm{~S}$ was too small.

The results of all $t_{R B T}$ at $40 \%, 60 \%$ and $80 \%$ DOD showed an increasing amount of recovered capacity for all discharged current rates. The recoverable capacity increased with higher DOD levels due to the increase of the $L_{2} S$ concentration and the diffusion of polysulfides to the active surface. Therefore, the recovered capacity dominated the contrary mechanism between the recovered capacity during the $t_{R B T}$ and decreasing inner cell temperature during $t_{R B T}$. The recovered capacity due to the unblocked active material increased the discharged capacity more than the discharged capacity was reduced by lower inner cell temperature. As expected, the recovered capacity highly increased with higher DOD, with higher discharge current and with higher $t_{R B T}$. Up to $20 \%$ of the cell capacity was recovered due to the concentration of $L i_{2} S$ and the amount of blocked active material.

The measurements for every DOD and discharge current were separately modeled by a first order differential equation, which was solved in Equation (5). The final recovery capacities of these separate models at $t_{R B T}=120 \mathrm{~min}$ are nonlinearly related, as we illustrate in Figure 6 .

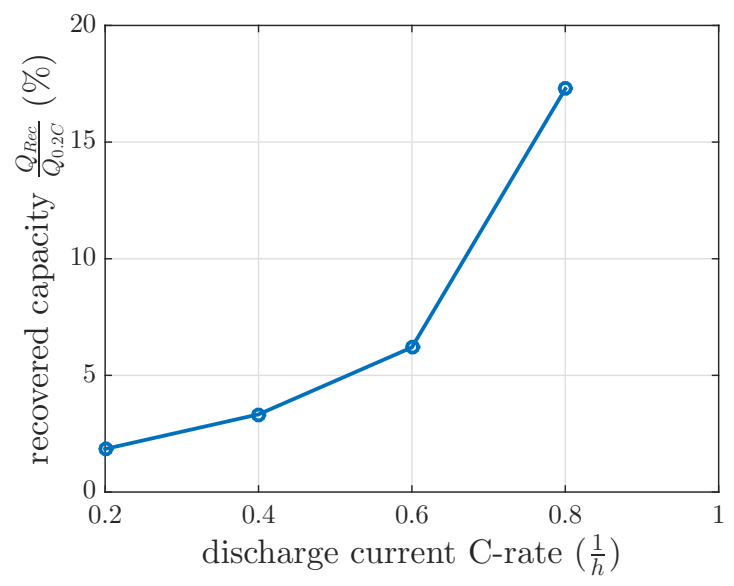

Figure 6. Measured recovered capacity for $120 \mathrm{~min} t_{R B T}$ at DOD $60 \%$ at $0.2 \mathrm{C}, 0.4 \mathrm{C}, 0.6 \mathrm{C}$ and $0.8 \mathrm{C}$ and at a constant temperature of $25^{\circ} \mathrm{C}$.

Furthermore, the results of Figure 5 and Table 1 present a mean time constant $\bar{\tau}$ within the range of 17.9 and $24.4 \mathrm{~min}$. This is in the same range as the published time constant in [9].

Table 1. Discharge current-dependent mean time constant $\bar{\tau}$ of Equation (5) measured at a constant temperature of $25^{\circ} \mathrm{C}$.

\begin{tabular}{cccc}
\hline & $\boldsymbol{I}_{\mathbf{0 . 2} \mathrm{C}}$ & $\boldsymbol{I}_{\mathbf{0 . 4} \mathrm{C}}$ & $\boldsymbol{I}_{\mathbf{0 . 8 \mathrm { C }}}$ \\
\hline $\bar{\tau}$ & 17.9 & 24.4 & 21.6 \\
\hline
\end{tabular}


In order to quantify the modeled quality, the root mean square of the recovery model for every discharge current and every DOD is shown in Table 2. This shows that the highest error of the model was at $60 \%$ DOD. Good agreements were given for $20 \%$ and $80 \%$.

Table 2. Root mean square error between measured and modeled recovered capacity, normalized by the nominal discharge capacity at $0.2 \mathrm{C}$ and measured at a constant temperature of $25^{\circ} \mathrm{C}$.

\begin{tabular}{ccccc}
\hline Discharge Current & $\mathbf{2 0} \%$ DOD & $\mathbf{4 0} \%$ DOD & $\mathbf{6 0} \%$ DOD & $\mathbf{8 0} \%$ DOD \\
\hline $0.2 \mathrm{C}$ & $0.04 \%$ & $0.01 \%$ & $0.07 \%$ & $0.08 \%$ \\
$0.4 \mathrm{C}$ & $0.09 \%$ & $0.10 \%$ & $0.42 \%$ & $0.1 \%$ \\
$0.8 \mathrm{C}$ & $0.08 \%$ & $0.35 \%$ & $0.48 \%$ & $0.28 \%$ \\
\hline
\end{tabular}

In order to test the modeled capacity recovery effect, the same recovery cycle as described in Section 3.2 was applied for a discharge current of $0.6 \mathrm{C}$ with a $t_{R B T}$ of $120 \mathrm{~min}$ at $60 \%$ DOD. This investigation intended to test the feasibility of the model interpolation between the measured discharge current of $0.4 \mathrm{C}$ and $0.8 \mathrm{C}$. The measured recovered capacity in this recovery cycle was $6.2 \%$ (see Figure 6 ), whereas the modeled recovery capacity was $9.5 \%$ by interpolating the recovery model between $0.4 \mathrm{C}$ and $0.8 \mathrm{C}$. If the modeled recovered capacity between $0.2 \mathrm{C}$ and $0.4 \mathrm{C}$ were extrapolated, the modeled recovery capacity would be $4.75 \%$ for this $0.6 \mathrm{C}$ investigation. These recovery capacities did not fit the measured ones for interpolation or extrapolation. Therefore, a linear interpolation of the recovered capacity at $0.4 \mathrm{C}$ of constant current investigation and at $0.8 \mathrm{C}$ of the first recovery time constant investigation in Section 3.1 was used and showed that the measured recovered capacity of $0.6 \mathrm{C}$ was reasonable. Therefore, the gain of the first recovery time constant investigation was interpolated between 100\% DOD and 60\% DOD with respect to the DOD dependent gain results in our measurements in Figure 5. A recovery capacity of 5.6\% was calculated by this model interpolation. The measured recovered capacity of $6.2 \%$ at $0.6 \mathrm{C}$ was higher, as our model predicted, but reasonable with respect to Table 2 .

\subsection{Drive Cycle Condition}

In this section, time-variant currents are investigated based on a drive cycle. Due to the fact that the recovered capacity is interesting for vehicular applications, a drive cycle with a LiS traction battery was investigated. This LiS traction battery was downsized on the cell level and measured in our lab.

Today, $68 \%$ of the daily travel of light-duty vehicles is about 40 miles per day [16]. The electric vehicle journey time is short compared to rest time periods. In vehicular applications, these rest time periods have an important influence on the usable cell capacity and DOD in LiS batteries due to the recovery effect. Therefore, the basic recovery model was tested at separate cells with two different time-variant current profiles based on the US06 drive cycle. This drive cycle was already used in [17] because of the high amount of recuperation parts. It showed a maximum possible real condition opposite to a recovery effect based on constant current discharge. The drive cycle and the used current profile are shown in Figure 7. This US06 drive cycle was used to calculate current profiles for commercial LiS cells. The current profile as shown in Figure 7 was separately scaled to a maximum discharge current of $0.5 \mathrm{C}$ and $1 \mathrm{C}$ by a light-duty vehicle.

Each cell was discharged with repetitions of one of the two scaled current profiles of the US06 drive cycle. These repeated current profiles discharged the cell to the same DOD levels as described in Section 3.3. At these DOD levels, a $t_{R B T}$ of 120 min was included in order to check the maximum recovered capacity. Afterwards, the cell was further discharged at repeated current profiles of the scaled US06 current profile. The results presented in Figure 8 show the expected negative recovered capacity at 20\% DOD. Beside this, the results for the 1 C US06 at $60 \%$ and $80 \%$ DOD were unexpectedly high. At $80 \%$ DOD, it showed a recovered capacity of $8 \%$. The results of the scaled 0.5 C US06 drive cycle fit the 0.5 C US06 mean current of the current profile $\left(I_{\mathrm{US} 060.5 \mathrm{C}}=-0.14 \mathrm{C}\right)$, whereas the recovered capacities of the scaled 1 C US06 drive cycle highly differed from the modeled recovered capacity by 
the $1 \mathrm{C}$ US06 mean current $\left(\overline{\mathrm{I}}_{\mathrm{US06} 1 \mathrm{C}}=-0.27 \mathrm{C}\right)$. The modeled recovered capacity at a constant discharge current of $0.27 \mathrm{C}$, which equivalents to $\bar{I}_{\mathrm{US} 061 \mathrm{C}}$ at $80 \%$ DOD and $t_{R B T}$ of $120 \mathrm{~min}$ is $3.2 \%$. This is lower than the measured one (see Figures 5 and 8). The calculated mean currents of the drive cycle considered each current $I_{\mathrm{USO6}(\mathrm{t})}$ by the same weight.
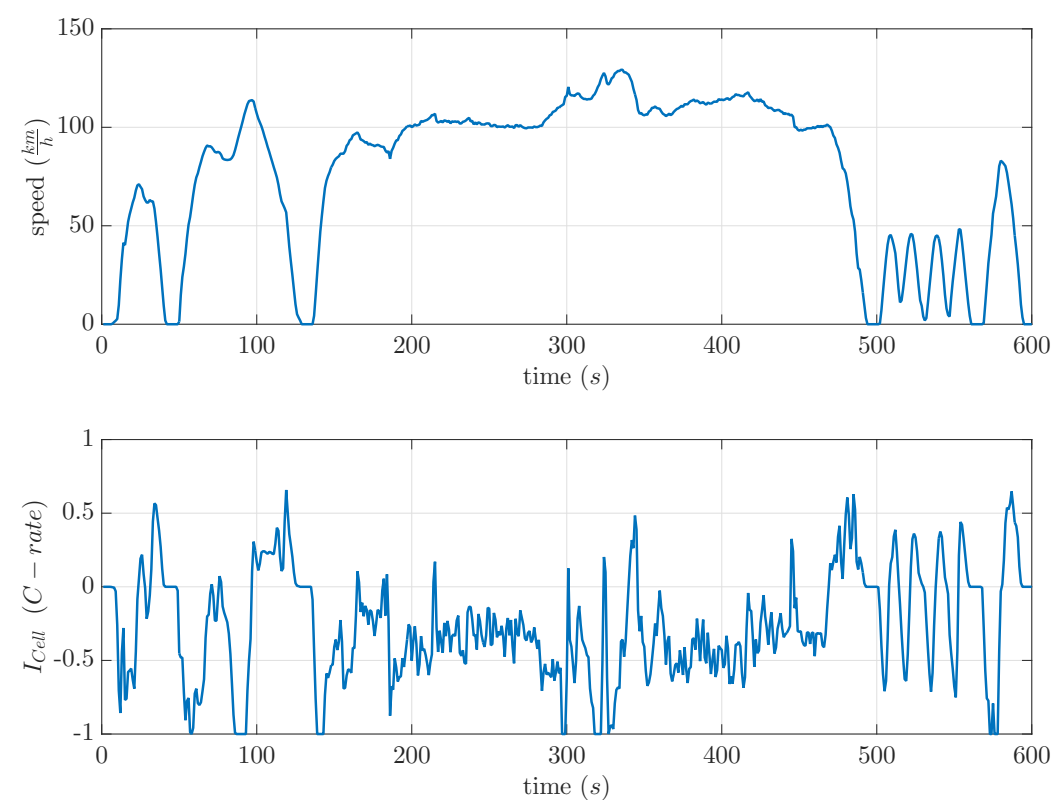

Figure 7. Velocity and calculated current profile of the US06 drive cycle. Discharged current is negative.

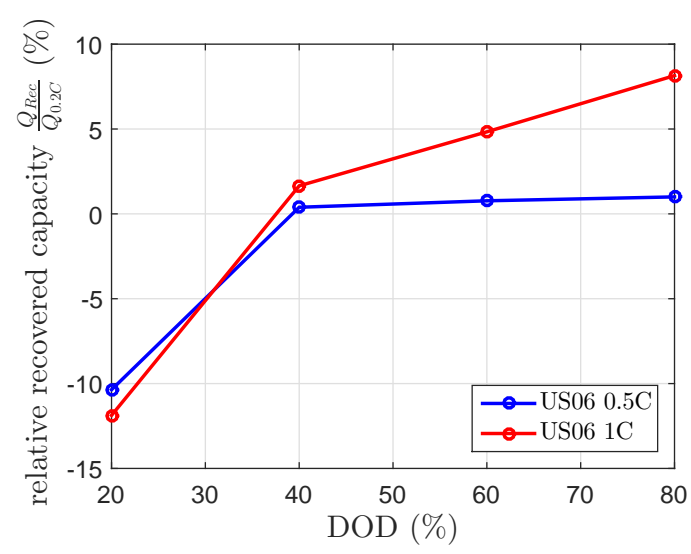

Figure 8. Relative recovered cell capacity by the US06 drive cycle for a maximum discharge current of $0.5 \mathrm{C}$ and $1 \mathrm{C}$, measured at a constant temperature of $25^{\circ} \mathrm{C}$.

\subsection{Discussion}

Our study demonstrates a DOD and current-dependent capacity recovery effect. Obviously, the findings in the constant current investigation in Section 4.1 show a first order differential equation behavior for constant currents.

As Section 4.1 shows, the recovered capacity of $0.6 \mathrm{C}$ is underestimated by model extrapolation between $0.2 \mathrm{C}$ and $0.4 \mathrm{C}$, and it is overestimated by model interpolation between $0.4 \mathrm{C}$ and $0.8 \mathrm{C}$. A reasonable recovered capacity can be estimated with respect to the first recovery time constant investigation. This can be explained by assuming that the recovered capacity of the $0.8 \mathrm{C}$ model is too high. The findings of the recovered capacity for discharge current at $0.8 \mathrm{C}$ for $60 \%$ and for $80 \%$ DOD of up to $20 \%$ seem to be too high compared to the maximum of $10.5 \%$ recovered capacity of the first recovery time constant investigation in Section 3.1. One explanation for the finding of this high 
recovered capacity might be an increasing age of the cell. The decreased discharge capacity of the cell at high currents is more influenced than at low currents. Compared to constant current discharge, the discharge with $t_{R B T}$ at a higher aged state could recover some capacity and, in addition, might use dissolved non-utilized polysulfides, which diffuse back to the active surface. However, the normalized recovered capacity is in the same range as the normalized recovered capacity in [9] at $1 \mathrm{C}$. Contrary to the results in [9], we could not recover the whole non-utilized sulfur capacity. The difference in our study and the findings of [9] might also be that the $t_{R B T}$ is included at $100 \%$ DOD in [9] and at a maximum of $80 \%$ DOD in our study. A further explanation could be due to different cell designs. Further investigations on the recovery effect and aging have to be made.

Although there are some higher root mean square errors for data of $60 \%$ DOD in comparison to the root mean square errors of the other DODs (see Table 2), they still seem reasonable compared to the amount of recovered capacity and to the other model errors.

Our data in Table 1 confirm that $\tau$ at different DOD levels suit the recovery time constant of $100 \%$ DOD published in [9]; although they are very small at $0.2 \mathrm{C}$.

Our additional results at drive cycle conditions offer evidence that the provided model cannot estimate recovered capacity of time-variant currents due to current averaging before $t_{R B T}$. The assumption of equally-weighted current on the recovery effect is not feasible. The $1 \mathrm{C}$ US06 drive cycle provided a remarkably higher recovered capacity than estimated by current averaging. The difference between the actual recovered capacity and the estimated recovered capacity due to current averaging is probably due to the nonlinearity of the $L_{2} S$ blocking process by time-variant currents. The constant current investigation provides little information about this blocking process due to time-variant currents. It seems that 0.5 C US06 does not heavily influence the recovery effect due to time-variant currents.

We readily acknowledge that this model is limited to constant current discharge profiles. We therefore recommend further investigations towards dynamic current discharge profiles. An alternative to the averaged current as the input parameter for the recovery model might be the grade of blocked active material.

However, the present study offers clear evidence that the recovery effect is an important mechanism to be considered in vehicular applications.

\section{Conclusions}

In our capacity recovery study, we have provided valuable results on the impact of recovery break time on usable capacity in LiS batteries at different DODs. We have shown that it is possible to build an applicable capacity recovery model with respect to DOD, discharge current and recovery break time. Moreover, the recovered capacity highly increases with the increasing of every single one of these parameters.

Our study has shown that the highly current-dependent LiS capacity can be recovered by a maximum amount of $20 \%$ of the nominal cell capacity at $0.8 \mathrm{C}$ and $80 \%$ DOD. However, the aging of cells seems to influence the recovered capacity. Therefore, this aging influence and this current rate are in the focus of our current researches.

The investigation showed negative recovered capacities at 20\% DOD for every recovery break time and discharge current due to a low concentration of precipitated $L_{2} S$ and a reduction of inner cell temperature during the recovery break time. At this DOD, more capacity is useable by reducing recovery break times. A positive capacity is recovered for 40\% DOD and higher. This recovered capacity is increasing with DOD and discharge current until a maximum recovery break time of $120 \mathrm{~min}$. The recovered capacity was modeled by a first order differential equation.

Although this investigation provides a basic recovery model, there are still open questions for further research on the recovery effect in LiS cells. The model calculated at constant current discharges could not estimate a drive cycle properly with time-variant currents. The recovered capacity from the drive cycle and consequently from time-variant currents was remarkably high. We therefore 
recommend that weighted time-variant currents be used to properly estimate the capacity recovery in future research.

Nevertheless, the investigation shows that the capacity recovery effect is an important effect to estimate the true usable capacity properly in LiS batteries for vehicular and other applications.

Author Contributions: C.M. and W.C. conceptualized the study. C.M. developed the methodology, performed the investigation, validated the measurements and wrote the original draft. W.C. and A.J. supervised the study. W.C., A.H. and A.J. edited and reviewed the paper. W.C. and A.H. provided resources.

Funding: This research received no external funding.

Conflicts of Interest: The authors declare no conflict of interest.

\section{References}

1. Urbonaite, S.; Poux, T.; Novák, P. Progress Towards Commercially Viable Li-S Battery Cells. Adv. Energy Mater. 2015, 5, 1500118 . [CrossRef]

2. VDI. Available online: https://www.vdi.de/ (accessed on 24 June 2017).

3. Barghamadi, M.; Kapoor, A.; Wen, C. A Review on Li-S Batteries as a High Efficiency Rechargeable Lithium Battery. J. Electrochem. Soc. 2013, 160, 1256-1263. [CrossRef]

4. Busche, M.R.; Adelhelm, P.; Sommer, H.; Schneider, H.; Leitner, K.; Janek, J. Systematical electrochemical study on the parasitic shuttle-effect in lithium-sulfur-cells at different temperatures and different rates. J. Power Sources 2014, 259, 289-299. [CrossRef]

5. Kolosnitsyn, V.S.; Kuzmina, E.V.; Karaseva, E.V. On the reasons for low sulfur utilization in the lithium-sulfur batteries. J. Power Sources 2015, 274, 203-210. [CrossRef]

6. Mikhaylik, Y.V.; Akridge, J.R. Polysulfide Shuttle Study in the Li/S Battery System. J. Electrochem. Soc. 2004, 151, 1969-1976. [CrossRef]

7. Waluś, S.; Barchasz, C.; Bouchet, R.; Leprêtre, J.C.; Colin, J.F.; Martin, J.F.; Elkaïm, E.; Baehtz, C.; Alloin, F. Lithium/sulfur Batteries Upon Cycling: Structural Modifications and Species Quantification by In Situ and Operando X-ray Diffraction Spectroscopy. Adv. Energy Mater. 2015, 27, 5203-5209. [CrossRef]

8. Jongerden, M.R.; Haverkort, B.R. Battery Modeling; Technical Report TR-CTIT-08-01; Centre for Telematics and Information Technology, University of Twente: Enschede, The Netherlands, 2008.

9. Zhang, T.; Marinescu, M.; Walus, S.; Offer, G.J. Modelling transport-limited discharge capacity of lithium-sulfur cells. Electrochim. Acta 2016, 219, 502-508. [CrossRef]

10. Parfitt, C. Characterisation, Modelling and Management of Lithium-Sulphur Batteries for Spacecraft Applications. Ph.D. Thesis, University of Warwick, Coventry, UK, 2012.

11. Knap, V.; Stroe, D.I.; Teodorescu, R.; Swierczynski, M.; Stanciu, T. Electrical circuit models for performance modeling of Lithium-Sulfur batteries. In Proceedings of the Energy Conversion Congress and Exposition (ECCE), Montreal, QC, Canada, 20-24 September 2015.

12. Kumaresan, K.; Mikhaylik, Y.; White, R.E. A Mathematical Model for a Lithium-Sulfur Cell. J. Electrochem. Soc. 2008, 155, A576-A582. [CrossRef]

13. Marinescu, M.; Zhang, T.; Offer, G.J. A zero dimensional model of lithium-sulfur batteries during charge and discharge. Phys. Chem. Chem. Phys. 2015, 18, 584-593. [CrossRef] [PubMed]

14. Zhang, S.S. Liquid electrolyte lithium/sulfur battery: Fundamental chemistry, problems, and solutions. J. Power Sources 2013, 231, 153-162. [CrossRef]

15. Hancock, K.; Hagen, M.; Fanz, P.; Joos, M.; Müller, D.; Abert, M.; Tübke, J. Electrolyte decomposition in Li-S cells. In Proceedings of the Li-SM3 Conference, London, UK, 26-27 April 2017.

16. Howell, D. Update on US DOE Electric Drive Vehicle R\&D and Deployment Activities. In Proceedings of the 6th US-China Electric Vehicle and Battery Technology Workshop, Boston, MA, USA, 22-24 August 2012.

17. Keil, P.; Jossen, A. Aging of Lithium-Ion Batteries in Electric Vehicles: Impact of Regenerative Braking. In Proceedings of the 28th EVS, Goyang, Korea, 3-6 May 2015.

(C) 2018 by the authors. Licensee MDPI, Basel, Switzerland. This article is an open access article distributed under the terms and conditions of the Creative Commons Attribution (CC BY) license (http:/ / creativecommons.org/licenses/by/4.0/). 